\title{
Technical note: Mammary gland ultrasonography to evaluate mammary parenchymal composition in prepubertal heifers
}

\author{
R. L. Albino, ${ }^{\star}$ S. E. F. Guimarães, ${ }^{*}$ K. M. Daniels, † M. M. S. Fontes, ${ }^{*}$ A. F. Machado, ${ }^{*}$ G. B. dos Santos, $\ddagger$ \\ and M. I. Marcondes*1 \\ *Universidade Federal de Viçosa, Viçosa, MG, Brazil, 36570-900 \\ †Dairy Science Department, Virginia Polytechnic Institute and State University, Blacksburg 24061 \\ †Programa de Pós Graduação em Clínica e Reprodução da Universidade Federal Fluminense, Niterói, RJ, Brazil, 24230340
}

\begin{abstract}
Bovine mammary gland development studies are often terminal or involve invasive biopsy procedures. Therefore, noninvasive means of assessing mammary development should be considered as alternative methods in live animals. The objective was to test if mammary ultrasonography can be used as a noninvasive way to estimate mammary parenchyma (PAR) composition in prepubertal dairy heifers with different average daily body weight gains. In the $84 \mathrm{~d}$ preceding, the ultrasound exam heifers were maintained in 1 of 3 treatment groups. Individual heifers were fed a high gain $(1 \mathrm{~kg} / \mathrm{d} ; \mathrm{n}=6)$, low gain $(0.5 \mathrm{~kg} / \mathrm{d}, \mathrm{n}=6)$, or maintenance $(n=6)$ treatment diet. To achieve desired body weight gains, heifers were fed differing amounts of the same silage-based diet. Mammary glands of 18 crossbred heifers Holstein:Gyr underwent a single mammary ultrasound exam immediately before heifer slaughter, which took place when heifers weighed 142.0 $\pm 8.0 \mathrm{~kg}$ and were $200 \mathrm{~d}$ old. The 4 mammary glands of each heifer were evaluated using a real-time B-mode ultrasound machine equipped with a $6.5-\mathrm{MHz}$ microconvex transducer. Digital images (8-bit) of glands were obtained and PAR was identified within gland. Average pixel values per unit of PAR area were determined for each gland and analyzed at the level of heifer. Pixel results were interpreted on the basis that lower average pixel values reflect PAR with relatively high amounts of protein as opposed to fat. To help validate that the pixel value within PAR is associated with composition of PAR, pixel findings were compared with histological [number of adipocytes in PAR (Nad) and epithelial area in PAR (Ep)] and biochemical [percent crude protein in PAR (\%CP), percent ether extract in PAR (\%EE), PAR weight (WPAR), and mammary fat pad weight (WFAT)] composition of PAR in these same heifers. Within PAR, \%EE and WFAT were positively
\end{abstract}

Received June 27, 2016.

Accepted October 29, 2016.

${ }^{1}$ Corresponding author: marcosinaciomarcondes@gmail.com correlated with pixel values, whereas \%CP, Ep, and Nad were negatively correlated. Parenchyma weight did not correlate with pixel values. Regression analyses (fixed effect log-pixel value; random effect treatment) were used to estimate Nad, Ep, \%CP, \%EE, WPAR, and WFAT. Sensitivity analysis of regression equations revealed that accuracy of tested equations ranged from 0.77 to 0.93 and precision ranged from 0.56 to 0.82 . Concordance correlation coefficients of the equations ranged from 0.41 to 0.76 . In conclusion, ultrasonography of PAR can accurately measure and predict PAR composition in prepubertal dairy heifers growing at various rates of gain.

Key words: dairy heifer, ultrasound, mammary gland

\section{Technical Note}

Mammary glands consist of 2 major types of tissues that serve different functions. As summarized by Esselburn et al. (2015), these are (1) epithelial tissue and surrounding stromal elements, collectively called mammary parenchyma (PAR), and (2) stromal tissue that lies adjacent to PAR and does not contain epithelial structures, and instead mainly consists of connective tissue structures such as adipose. For this reason, mammary stroma is often referred to as mammary fat pad.

Understanding of growth dynamics of these mammary tissues as well as the influence of nutrition on mammary gland development has been the subject of study over the years (Sejrsen et al., 1983; Brown et al., 2005; Meyer et al., 2006). Esselburn et al. (2015) recently showed that in heifers younger than 2 mo of age, obtaining weekly PAR measurements via ultrasound was an effective quantitative tool for measuring changes in PAR area in vivo. Although estimation of PAR composition via ultrasonography was not an experimental objective of Esselburn et al. (2015), those authors noted that such estimation is feasible. That was the motivation for our current work and is a distinguishing feature of this study.

Ultrasound has been widely used in the meat industry to monitor both subcutaneous fat thickness and 
intramuscular fat accumulation (Williams, 2002). The measurement of intramuscular fat accumulation in carcasses is possible due to differences in the way that fat and protein reflect sound waves in body tissues (Brethour, 1990).

Our hypothesis was that mammary ultrasonography can be used as a noninvasive way to estimate PAR composition in prepubertal dairy heifers with different ADG.

The study was conducted in the Animal Science Department of the Universidade Federal de Viçosa, Viçosa-MG. The institutional ethics committee approved all procedures (protocol number, 20/2015). Eighteen crossbred heifers Holstein:Gyr were used in this experiment; they were part of a larger experiment that dealt with effects of nutrient intake on mammary growth and composition. Full experimental details are reported elsewhere (Weller et al., 2016). Briefly, heifers were allotted to 1 of 3 dietary treatments when they were 3 to $4 \mathrm{mo}$ of age (BW, $102.2 \pm 3.4 \mathrm{~kg}$ ). Treatments were high gain $[\mathbf{H G}(\mathrm{n}=6) ; 1.0 \mathrm{~kg} / \mathrm{d}$ of $\mathrm{BW}$ gain], low gain [LG $(\mathrm{n}=6) ; 0.5 \mathrm{~kg} / \mathrm{d}$ of $\mathrm{BW}$ gain], and maintenance [MA $(\mathrm{n}=6) ; 0.0$ to $0.1 \mathrm{~kg} / \mathrm{d}$ of $\mathrm{BW}$ gain]. The MA treatment was kept slightly above 0.0 $\mathrm{kg} / \mathrm{d}$ of ADG to avoid mobilization of body tissues. To achieve desired BW gains, heifers were fed differing amounts of the same silage-based diet. The amount of ration offered was adjusted every 2 wk based on heifer BW gains. Heifers were housed and fed individually; the experimental unit was heifer.

At the end of the 84-d experiment, heifers were slaughtered $(140.0 \pm 8.0 \mathrm{~kg}$ and $200 \mathrm{~d}$ old $)$ to assess body and mammary composition (Weller et al., 2016). Relevant dependent variables reported by Weller et al. (2016) and also used here include number of adipocytes in PAR (Nad), epithelial area (Ep), percent crude protein of PAR $(\mathbf{\%} \mathbf{C P})$, percent ether extract of PAR (\%EE), PAR weight (WPAR), and mammary fat pad weight (WFAT) in these same heifers. For full description of methodology on these 6 dependent variables, the reader is directed to Weller et al. (2016).

The 4 mammary glands of each heifer were evaluated in a single ultrasound exam before slaughter using a real-time B-mode ultrasound machine equipped with a $6.5-\mathrm{MHz}$ micro-convex transducer (DP2200, Mindray, Shenzhen, China). Heifers remained standing for the ultrasound exam; sedatives were not used. Commercial acoustic gel (Chattanooga Group Inc., Chattanooga, $\mathrm{TN}$ ) was applied to each gland before ultrasounding. A single operator performed all ultrasound exams.

With the heifer restrained in a standing position, the lubricated micro-convex transducer was applied to the base of each teat at a $45^{\circ}$ angle, in a caudal-to-cranial placement (Figure 1A). This procedure was obtained from Nishimura et al. (2011) and adapted (Albino et al., 2015).

Still image capture software available on the ultrasound machine was used to capture two 8-bit digital images for each gland (Figure 1B). These images were visually inspected and the image with the best PAR definition was chosen; subsequent evaluations were done based on 4 images per heifer.

The PAR within each digital image was evaluated using ImageJ software (National Institutes of Health, Bethesda, MD). The PAR is hypoechoic (black) on ultrasound when compared with the mammary fat pad (Esselburn et al., 2015), which is hyperechoic (white). Therefore, the most hypoechoic region of each image was identified as PAR (Figure 1B). Within the area identified as PAR (3 squares each measuring $0.4 \mathrm{~cm}^{2}$ ) were randomly overlaid onto the image in ImageJ (Figure 2).

Finally, an average pixel value per unit area was determined for each square using a conversion factor in Image J $(1 \mathrm{~cm}=50$ pixels $)$. In 8-bit images, each pixel is numerically represented on a scale of 256,000
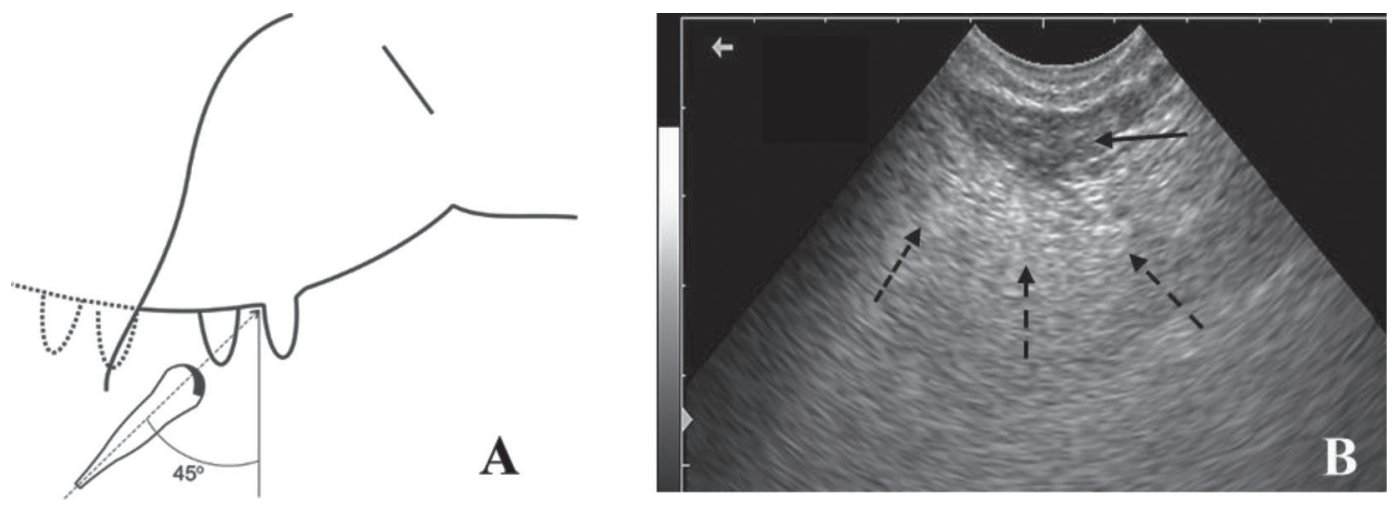

Figure 1. Drawing of the probe position at the heifer's mammary gland (Albino et al., 2015; A) and ultrasound image (B) with dashed arrows representing the mammary fat pad and solid arrows representing the parenchymal area. 
shades of gray $(0=$ black; $255,000=$ white $)$ according to their brightness (Ferreira and Rasband, 2011). Therefore, an area of $0.4 \mathrm{~cm}^{2}$ with an average pixel value of 100,000 is blacker (more hypoechoic) than a similar square with a value of 200,000 . Further, this variation of gray shades is related to reflection capacity of sound waves imparted by the tissue. Fat tissue has greater reflectivity of sound waves, producing more hyperechoic or white images. On the other hand, protein has lower reflectivity, thereby producing hypoechoic or blacker images (Brethour, 1990). Thus, squares with lower average pixel values should reflect PAR with relatively high amounts of protein as opposed to fat. Finally, to match mammary composition data, which were collected at the level of udder, the 12 average pixel values per heifer were summed and divided by 12 .

Pixel data from mammary glands were log-transformed before statistical analysis to satisfy rules of ANOVA (Davis and Stephens, 1989; data not shown).

To evaluate the relationship between dependent variables, a regression analysis was used that included the fixed effect of $\log$ of pixel values and the random effect of treatment (HG, LG, and MA) to estimate Nad, Ep, $\% \mathrm{CP}, \% \mathrm{EE}$, WPAR, and WFAT using PROC MIXED (SAS 9.3, 2011, SAS Institute Inc., Cary, NC).

Subsequently, a sensitivity analysis was performed by cross-validation (Davison and Hinkley, 1997) to estimate the mean square error prediction (MSEP), correlation coefficient $(\boldsymbol{\rho})$, accuracy $\left(\mathbf{C}_{b}\right)$, coefficient of determination $\left(\mathrm{R}^{2}\right)$, and concordance correlation coefficient (CCC) of each empirical equation using $R$ statistical software (R Development Core Team, 2009). The procedure was repeated 1,000 times, and means of MSEP, CCC, $\rho, \mathrm{C}_{b}$, and $\mathrm{R}^{2}$ are shown in Table 1 .

The $\% \mathrm{EE}$ in PAR was positively $(\mathrm{r}=0.318 ; P=$ $0.024)$ correlated with pixel value in PAR. This was as expected because high pixel values are associated with image whiteness, which equates with fat here. In

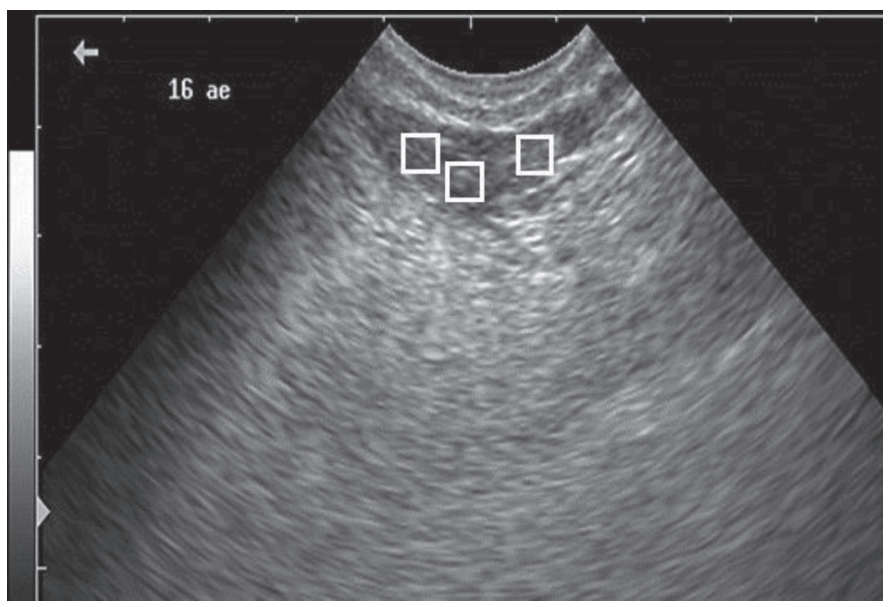

Figure 2. Demonstration of square positioning used to evaluate pixel value in mammary parenchyma with Image J (National Institutes of Health, Bethesda, MD). Each square is $0.4 \mathrm{~cm}^{2}$.

agreement, \%CP of PAR was negatively correlated $(\mathrm{r}=$ $0.467 ; P=0.006)$ with pixel value.

No relationship was observed between pixel value and WPAR $(P=0.645)$. We believe that the high animal-to-animal variation in WPAR may have masked any effect. A positive linear relationship was identified between pixel value and WFAT $(\mathrm{r}=0.596 ; P=0.013)$, which indicates a similar effect as observed in \%EE noted above (Table 1).

Similarly, relationships between pixel value and Ep $(\mathrm{r}=0.529 ; P=0.001)$ and $\mathrm{Nad}(\mathrm{r}=0.672 ; P<0.001)$ were both identified as negative, that is, as pixel value increased Ep and Nad decreased. This result is consistent with PAR composition that is mainly formed by epithelial and adipose tissue (Weber et al., 2000). The negative relationship between pixel value and Nad is explained by the low deposition of triglyceride within PAR adipocytes of animals with restricted energy consumption (in this case, MA), which leads to a lower

Table 1. Sensitivity analysis of parenchymal components of dairy heifers estimated by ultrasonography

\begin{tabular}{|c|c|c|c|c|c|c|}
\hline Item $^{1}$ & $\% \mathrm{EE}$ & $\% \mathrm{CP}$ & WFAT & WPAR & Ep & Nad \\
\hline$\beta_{0}$ & $-0.001 \pm 0.35$ & $1.38 \pm 0.39$ & $-14,287 \pm 4,689$ & $-516.39 \pm 1,609$ & $457.27 \pm 105.61$ & $11,338 \pm 1,705$ \\
\hline$\beta_{1}$ & $0.078 \pm 0.03$ & $-0.11 \pm 0.03$ & $1,321 \pm 414$ & $66.67 \pm 141$ & $-37.70 \pm 9.28$ & $-948.59 \pm 149$ \\
\hline$P$-value & 0.024 & 0.006 & 0.013 & 0.645 & 0.001 & $<0.001$ \\
\hline MSEP & 0.0003 & 0.0002 & $43,658.27$ & $7,719.63$ & 28.17 & $6,887.93$ \\
\hline \multicolumn{7}{|l|}{ Partition of MSEP, \% } \\
\hline Mean bias & 7.18 & 7.89 & 8.94 & 7.87 & 8.19 & 9.36 \\
\hline Systematic bias & 6.73 & 10.90 & 15.15 & 6.76 & 14.35 & 10.33 \\
\hline Random error & 86.08 & 81.20 & 75.91 & 85.36 & 77.45 & 80.31 \\
\hline $\mathrm{CCC}$, range 0 to 1 & 0.413 & 0.555 & 0.687 & 0.015 & 0.615 & 0.764 \\
\hline$\rho$ & 0.564 & 0.684 & 0.772 & 0.053 & 0.727 & 0.820 \\
\hline $\mathrm{C}_{b}$ & 0.773 & 0.829 & 0.906 & 0.271 & 0.914 & 0.938 \\
\hline $\mathrm{R}^{2}$ & 0.318 & 0.467 & 0.596 & 0.073 & 0.529 & 0.672 \\
\hline
\end{tabular}

${ }_{1} \% \mathrm{EE}=$ percentage of ether extract in mammary parenchyma $(\mathrm{PAR}) ; \% \mathrm{CP}=$ percentage of crude protein in PAR; WFAT $=$ weight of extraparenchymal fat $(\mathrm{g})$; WPAR = weight of PAR $(\mathrm{g})$; Ep = area occupied by epithelial tissue in PAR; Nad = number of adipocytes in PAR. MSEP $=$ mean square error prediction; $\mathrm{CCC}=$ concordance correlation coefficient; $\rho=$ correlation coefficient; $\mathrm{C}_{b}=$ accuracy. 
area per adipocyte but a higher number of adipocytes per unit area (Azain, 2003). Thus, within similarly sized microscopic fields of view, a higher total number of PAR adipocytes was observed in MA compared with HG and LG, and these adipocytes contained less accumulated fat as evidenced by lower $\% \mathrm{EE}$ in the $\mathrm{MA}$ treatment (data not shown; Supplemental Table S1, https://doi.org/10.3168/jds.2016-11668).

One drawback of our technique worth mentioning is that our ultrasound images did not allow us to distinguish between epithelial duct tissue and duct lumens within PAR; both were observed as hypoechoic (black) features compared with the surrounding mammary fat.

From the sensitivity analysis, we observed that $75 \%$ of the average error prediction was related to random effects, possibly not controlled by the model, which in turn indicates a small proportion of error associated with the systematic error and bias of model estimates. The systematic error is concerning the direction of the curve predicted, and systematic bias is related to slope of linear regression, being both associated with prediction problems of the model. Therefore, good equations or models are expected to have a great proportion of error associated with random effects.

Equation precision varied from 0.56 to 0.82 , indicating that the models have limitations to properly predict similar values (Tedeschi, 2006). On the other hand, the models presented medium to high accuracy (0.772 to 0.938), showing the ability to predict the real mean values of pixels (Tedeschi, 2006). The CCC, which indicates the precision and accuracy of the technique, was not high; however, it is noteworthy that the number of observations used to establish the regression equations was low $(\mathrm{n}=18)$, which made it hard to increase the technique precision and directly affected the CCC (Table 1). However, even considering a small number of replications, the pixel values in PAR were correlated with 5 of 6 variables tested. Therefore, it may be inferred that ultrasound is an acceptable tool to assess and predict mammary gland composition in prepubertal heifers.

Ultrasonography of PAR can accurately measure and predict PAR composition in prepubertal heifers growing at various rates of gain. This is an important advancement in consistency of noninvasive monitoring of mammary development and may soon be used on dairy farms to monitor composition of PAR growth under various management scenarios. However, before largescale implementation, more studies involving greater numbers and sizes of animals are suggested to increase technique precision.

\section{ACKNOWLEDGMENTS}

The authors acknowledge the financial support of Coordenação de Aperfeiçoamento de Pessoal de Nível Superior (CAPES; Brasília, DF, Brazil), Conselho Nacional de Desenvolvimento Científico e Tecnológico (CNPq, Brazil), and Fundação de Amparo à Pesquisa do Estado de Minas Gerais (FAPEMIG, Brazil).

\section{REFERENCES}

Albino, R. L., M. I. Marcondes, R. M. Akers, E. Detmann, B. C. Carvalho, and T. E. Silva. 2015. Mammary gland development of dairy heifers fed diets containing increasing levels of metabolizable protein: Metabolizable energy. J. Dairy Res. 82:113-120.

Azain, M. J. 2003. Conjugated linoleic acid and its effects on animal products and health in single-stomached animals. Proc. Nutr. Soc. 62:319-328.

Brethour, J. R. 1990. Relationship of ultrasound speckle to marbling score in cattle. J. Anim. Sci. 68:2603-2613.

Brown, E. G., M. J. VandeHaar, K. M. Daniels, J. S. Liesman, L. T. Chapin, J. W. Forrest, R. M. Akers, R. E. Pearson, and M. S. Weber Nielsen. 2005. Effect of increasing energy and protein intake on mammary development in heifer calves. J. Dairy Sci. 88:595-603.

Davis, C. S., and M. A. Stephens. 1989. Algorithm AS 248: Empirical distribution function goodness-of-fit tests. J. R. Stat. Soc. Ser. C Appl. Stat. 38:535-543.

Davison, A. C., and D. V. Hinkley. 1997. Bootstrap Methods and Their Applications. Cambridge University Press, Cambridge, UK.

Esselburn, K. M., T. M. Hill, H. G. Bateman, F. L. Fluharty, S. J. Moeller, K. M. O'Diam, and K. M. Daniels. 2015. Examination of weekly mammary parenchymal area by ultrasound, mammary mass, and composition in Holstein heifers reared on 1 of 3 diets from birth to 2 months of age. J. Dairy Sci. 98:5280-5293.

Ferreira, T., and W. S. Rasband. 2011. ImageJ User Guide - IJ 1.46 Accessed Dec. 5, 2016. http://imagej.nih.gov/ij/docs/index.html.

Meyer, M. J., A. V. Capuco, D. A. Ross, L. M. Lintault, and M. E. Van Amburgh. 2006. Developmental and nutritional regulation of the prepubertal heifer mammary gland: I. Parenchyma and fat pad mass and composition. J. Dairy Sci. 89:4289-4297.

Nishimura, M., T. Yoshida, S. El-Khodery, M. Miyoshi, H. Furuokam, J. Yasuda, and K. Miyahara. 2011. Ultrasound imaging of mammary glands in dairy heifers at different stages of growth. J. Vet. Med. Sci. 73:19-24.

R Development Core Team. 2009. R: A language and environment for statistical computing. R Foundation for Statistical Computing, Vienna, Austria. http://www.R-project.org.

Sejrsen, K., J. T. Huber, and H. A. Tucker. 1983. Influence of amount fed on hormone concentrations and their relationship to mammary growth in heifers. J. Dairy Sci. 66:845-855.

Tedeschi, L. O. 2006. Assessment of the adequacy of mathematical models. Agric. Syst. 89:225-247.

Weber, M. S., S. Purup, M. Vestergaard, R. M. Akers, and K. Sejrsen. 2000. Regulation of local synthesis of insulin-like growth factor-I binding proteins in mammary tissue. J. Dairy Sci. 83:30-37.

Weller, M. M. D. C. A., R. L. Albino, M. I. Marcondes, W. Silva, K. M. Daniels, M. M. Campos, M. S. Duarte, M. L. Mescouto, F. F. Silva, and S. E. F. Guimarães. 2016. Effects of nutrient intake level of same diet on mammary parenchyma growth and gene expression in crossbreed (Holstein $\times$ Gyr) prepubertal heifers. J. Dairy Sci. 99:9962-9974.

Williams, A. R. 2002. Ultrasound applications in beef cattle carcass research and management. J. Anim. Sci. 80:E183-E185. 